\title{
Characterization and Incidence of the First Member of the Genus Mitovirus Identified in the Phytopathogenic Species Fusarium oxysporum
}

\author{
Almudena Torres-Trenas $(\mathbb{D}$ and Encarnación Pérez-Artés *(D) \\ Departamento de Protección de Cultivos, Instituto de Agricultura Sostenible (IAS), Consejo Superior de \\ Investigaciones Científicas (CSIC), 14004 Córdoba, Spain; a.torres.trenas@csic.es \\ * Correspondence: eperezartes@ias.csic.es
}

Received: 7 February 2020; Accepted: 2 March 2020; Published: 3 March 2020

\begin{abstract}
A novel mycovirus named Fusarium oxysporum f. sp. dianthi mitovirus 1 (FodMV1) has been identified infecting a strain of Fusarium oxysporum f. sp. dianthi from Colombia. The genome of FodMV1 is $2313 \mathrm{nt}$ long, and comprises a 172-nt 5'-UTR, a 2025-nt single ORF encoding an RdRp of 675 amino acid residues, and a 113-nt 3'-UTR. Homology BlastX searches identifies FodMV1 as a novel member of the genus Mitovirus in the family Narnaviridae. As the rest of mitoviruses, the genome of FodMV1 presents a high percentage of $\mathrm{A}+\mathrm{U}(58.8 \%)$ and contains a number of UGA codons that encode the amino acid tryptophan rather than acting as stop codons as in the universal genetic code. Another common feature with other mitoviruses is that the $5^{\prime}$ - and $3^{\prime}$-UTR regions of FodMV1 can be folded into potentially stable stem-loop structures. Result from phylogenetic analysis place FodMV1 in a different clade than the rest of mitoviruses described in other Fusarium spp. Incidence of FodMV1-infections in the collection of F. oxysporum f. sp. dianthi isolates analyzed is relatively high. Of particular interest is the fact that FodMV1 has been detected infecting isolates from two geographical areas as distant as Spain and Colombia.
\end{abstract}

Keywords: Fusarium oxysporum; hypovirulence; Mitovirus; mycovirus dispersion; Narnaviridae; viral RNA

\section{Introduction}

Fusarium oxysporum is a plant pathogenic fungus with worldwide distribution. This pathogenic species contains a diversity of host-plant specific forms (formae speciales) that cause vascular diseases in a large number of economically important crops. F. oxysporum f. sp. dianthi is the forma specialis of F. oxysporum that infects the carnation (Dianthus caryophillus). Carnation cultivation has a great economic importance in the cut flower sector [1,2], and its easy and rapid multiplication has made it the object of numerous commercialization of cuttings at international level. Until now, the various methodologies applied to the control of vascular wilt of the carnation have been ineffective.

Mycoviruses have been reported infecting all major taxonomic groups of fungi, including phytopathogenic and entomopathogenic fungi [3-14]. Although most of the mycoviruses described are cryptic, some species identified from different viral families show variable effects on the phenotype of their host isolate, including the induction of hypovirulence. The possibility of using these hypovirulence-inducing mycoviruses as biological control agents of the diseases caused by their fungal hosts has increased the interest for them [3-7,11,15-17]. Further, the advances in new high-throughput sequencing technologies and its low cost, are the key to the identification of new mycoviruses [18].

So far, the majority of mycoviruses described have a double-stranded RNA (dsRNA) genome, but a high number of single strand RNA (ssRNA) mycoviruses have also been discovered $[6,9,19]$. 
One of the most important families of ssRNA mycoviruses is the family Narnaviridae [19,20], which is constituted by two genera: Narnavirus and Mitovirus.

Mitoviruses have been identified in plants and in phytopathogenic and entomopathogenic fungi $[8,13,14,21-25]$. Mitoviruses have a genome formed by a single ssRNA molecule with a length from 2.3 to $2.9 \mathrm{~kb}$, although they are normally identified in their replicative form as dsRNA. These mycoviruses possess a unique open reading frame (ORF) that encodes an RNA dependent RNA polymerase $(\mathrm{RdRp})$ as the only protein $[19,20]$. All mitoviruses are non-encapsidated, and they are characterized by replicating within the mitochondria of the host $[20,26]$. Therefore, most of the genomes of viruses in the genus Mitovirus, like fungal and plant mitochondrial genomes, have a common property of A-U richness [27].

Although there are a few recent evidences that mycoviruses could be transmitted extracellularly, $[17,28,29]$, apparently mitoviruses are only transferred by hyphal anastomosis between vegetative compatible strains (horizontal transmission), in the case of fungi, and during the production of spores and seeds (vertical transmission), in the case of fungi and plants. Mitoviruses use also mitochondria as a mean to transfer from the mother cell to the daughter cell during cell division [20-23].

Normally, mitoviruses are cryptic, but in some cases, effects on the mitochondria morphology, on the in vitro growth, and on the virulence of the host fungus have been described [23-25,30-33]. Induction of hypovirulence associated to the infection by a mitovirus has been described in phytopathogenic fungi such as Botrytis cinerea [23], Cryphonectria. parasitica [30], Ophiostoma novo-ulmi [25], Sclerotinia homeocarpa [32], and Rhizoctonia solani [33].

Ten members of the genus Mitovirus have been identified infecting different species of Fusarium: Fusarium circinatum mitovirus 1 (FCMV1), Fusarium circinatum mitovirus 2-1 (FcMV2-1), and Fusarium circinatum mitovirus 2-2 (FcMV2-2) from different $F$. circinatum strains collected in the north of Spain [34]; Fusarium coeruleum mitovirus 1 (FcoMV1) and Fusarium globosum mitovirus 1 (FgMV1) from F. coeruleum and F. globosum strains from Japan [35]; Fusarium poae mitovirus 1 (FpMV1), Fusarium poae mitovirus 2 (FpMV2), Fusarium poae mitovirus 3 (FpMV3), and Fusarium poae mitovirus 4 (FpMV4), detected in a single strain of $F$. poae from Japan [36]; and Fusarium boothii mitovirus 1 (FbMV1) from a strain of F. boothii from Ethiopia [37]. Although no data have been reported on the possible effects of these mitoviruses on the phenotype of their hosts, FgMV1 seems to reduce the mycotoxin production of its host fungus [35].

In this work, we have analyzed a collection of Fusarium oxysporum f. sp dianthi isolates obtained from soil samples and diseased carnation plants from different geographic origins (Spain and Colombia). Apparently, a relatively high number of the isolates analyzed showed a putative viral infection with a similar banding pattern of dsRNA. Sequencing and analysis of this dsRNA shows that it corresponds to a novel mitovirus, the first one described infecting a F. oxysporum strain. Incidence of infections with this mitovirus in the collection analyzed has also been determined.

\section{Materials and Methods}

\subsection{Fungal Isolates and Culture Conditions}

A collection of 269 F. oxysporum f. sp. dianthi (Fod) isolates obtained between 2008 and 2012 from plant and soil samples in Spain (Cádiz and Seville provinces) and Colombia (Gachancipá, Department of Cundinamarca), was used in this study (Table 1). All isolates were characterized to race and molecular group using multiplex-PCR, as described in Gómez-Lama Cabanás et al. [38] (Table 1). All strains were stored at $-80{ }^{\circ} \mathrm{C}$ in glycerol, and propagated on potato dextrose agar (PDA) medium at $25^{\circ} \mathrm{C}$ in the dark. 
Table 1. Fusarium oxysporum $\mathrm{f}$. sp. dianthi isolates analyzed for the detection of viral infections.

\begin{tabular}{|c|c|c|c|c|}
\hline Isolate $(\mathbf{s})^{\mathrm{a}}$ & Geographic Origin ${ }^{b}$ & Source & Year & $\begin{array}{l}\text { Race-Group Assignation by } \\
\text { PCR Pattern c }\end{array}$ \\
\hline Fod $108,109,110,111,120,121$ & Chipiona(Ca) & Plant & 2008 & R1t \\
\hline Fod $112,113,114,117$ & Chipiona(Ca) & Plant & 2008 & R2I \\
\hline Fod 118,119 & Chipiona(Ca) & Plant & 2008 & R2II \\
\hline Fod 115 & Chipiona(Ca) & Plant & 2008 & - \\
\hline Fod 124, 127, 132, 134, 136, 138 & Chipiona(Ca) & Plant & 2009 & R2I \\
\hline Fod $122,128,130,140,142$ & Chipiona(Ca) & Plant & 2009 & R1t \\
\hline Fod $183,185,187$ & Chipiona(Ca) & Plant & 2010 & R2I \\
\hline Fod 181, 189, 191 & Chipiona(Ca) & Plant & 2010 & R1t \\
\hline Fod 179, 195, & Chipiona(Ca) & Soil & 2010 & R2II \\
\hline Fod 197 & Chipiona(Ca) & Soil & 2010 & R1t \\
\hline Fod $144,146,148,150,158,160,162,164$ & La Colonia(Se) & Plant & 2010 & R2I \\
\hline Fod 152,154 & Lebrija(Se) & Plant & 2010 & R1t \\
\hline Fod 156 & Lebrija(Se) & Plant & 2010 & R2II \\
\hline Fod 223, 225, 227, 229, 231, 233, 235, 237, 239, 241, 245, 247, 249, 251, 253 & Chipiona(Ca) & Plant & 2011 & R2I \\
\hline Fod 200, 201, 203, 205 & Chipiona(Ca) & Plant & 2011 & R1t \\
\hline Fod 271 & Chipiona(Ca) & Soil & 2011 & R2I \\
\hline Fod 256, 258, 259, 260, 261, 264, 265, 267, 269, 272, 275, 281 & Chipiona(Ca) & Soil & 2011 & R2II \\
\hline Fod 270,280 & Chipiona(Ca) & Soil & 2011 & R1t \\
\hline Fod 207, 210, 211, 213, 215, 217, 219, 221 & Lebrija(Se) & Plant & 2011 & R2I \\
\hline $\begin{array}{l}\text { Fod } 327,328,329,330,331,332,333,334,335,336,341.1,357,358,359,360,361,364,368 \\
373.2,433,434,435,436,453\end{array}$ & Chipiona(Ca) & Plant & 2012 & R2I \\
\hline Fod 365,452 & Chipiona(Ca) & Plant & 2012 & R2II \\
\hline Fod $341.2,342,343,344,345,346,347,348,349,350,351,363,366,367,371,372,373.1,471$ & Chipiona(Ca) & Plant & 2012 & R1t \\
\hline Fod $337,338,339,340,369,370,375,437,438,439,442,443,444,445,446,451,469$ & Chipiona(Ca) & Soil & 2012 & R2I \\
\hline Fod $362,376,440,441,447,448,450,454,459,463,476$ & Chipiona(Ca) & Soil & 2012 & R2II \\
\hline $\begin{array}{l}\text { Fod } 352,353,354,355,356,374,449,455,456,457,458,460,461,462,464,465,466,467 \\
468,470,472,473,474,475,477,478,479,480,481,482,483,484,485,486,487\end{array}$ & Chipiona(Ca) & Soil & 2012 & R1t \\
\hline Fod $383,384,385,386,387,388$ & Lebrija(Se) & Plant & 2012 & R2I \\
\hline Fod $377,378,379,380,381,382,391,392,393,394$ & Lebrija(Se) & Plant & 2012 & R1t \\
\hline Fod 400,402 & Lebrija(Se) & Soil & 2012 & $\mathrm{R} 2 \mathrm{I}$ \\
\hline Fod $389,390,395,403,404,405$ & Lebrija(Se) & Soil & 2012 & R2II \\
\hline Fod 396, 397, 398, 399, 401 & Lebrija(Se) & Soil & 2012 & R1t \\
\hline
\end{tabular}


Table 1. Cont.

\begin{tabular}{|c|c|c|c|c|}
\hline Isolate (s) $)^{\mathrm{a}}$ & Geographic Origin b & Source & Year & $\begin{array}{c}\text { Race-Group Assignation by } \\
\text { PCR Pattern c }\end{array}$ \\
\hline Fod $282,283,291,292,293,294,295,296,299,300,301,316,317,318,320,321,322,323$ & Colombia & Plant & 2012 & R1t \\
\hline Fod $303,304,305,306,307,308,309,310,311$ & Colombia & Plant & 2012 & R2I \\
\hline Fod $297,298,316,319,322$ & Colombia & Plant & 2012 & R2II \\
\hline Fod $284,287,288,289$ & Colombia & Soil & 2012 & R2II \\
\hline Fod $302,312,313,314,315$ & Colombia & Soil & 2012 & R2I \\
\hline Fod $285,286,290,324,325,326$ & Colombia & Soil & 2012 & R1t \\
\hline
\end{tabular}

${ }^{\mathrm{a}}$ Isolates were analyzed for the presence of viral infections by using agarose gel electrophoresis of the dsRNA extracts obtained by cellulose column chromatography ${ }^{\mathrm{b}} \mathrm{Ca}=\mathrm{Cádiz}$ province, $\mathrm{Se}=$ Sevilla province ${ }^{\mathrm{c}}$ Race-group assignation by specific-PCR amplification, as described in Gómez-Lama Cabanás et al. [38]. R1t = race 1 molecular group type, R2I $=$ race 2 molecular group I, R2II = race 2 molecular group II. (-) Unknown data 


\section{2. dsRNA Extractions}

Mitovirus-infected isolates were identified in dsRNA extracts. The dsRNA-enriched extracts were prepared from $3 \mathrm{mg}$ of the mycelia obtained after 7 days of growth in potato dextrose broth, as described in Lemus-Minor et al. [16]. The samples were pulverized in liquid nitrogen and suspended in $2 \times$ STE buffer (50mM Tris-HCl, pH 7.0, $0.1 \mathrm{M} \mathrm{NaCl}, 1 \mathrm{mM}$ EDTA), $10 \%$ SDS, and phenol. The total nucleic acids extracts obtained were then purified by cellulose column chromatography [39], and visualized by electrophoresis on 1\% agarose gels stained with RedSafe Nucleic Acid Staining Solution (iNtRON Biotechnology, Seongnamsi Gyeonggi-do, Korea).

\section{3. cDNA Synthesis, Cloning, and Sequencing}

The dsRNA identified was purified and subjected to reverse transcription (RT) and PCR amplification using random hexamer priming (Invitrogen, Carlsbad, CA, USA). The amplified products were cloned into the vector pCR Blunt (Invitrogen, Carlsbad, California, USA) and sequenced. Partial nucleotide sequences were used to design specific primers for the amplification by RT-PCR of the regions not covered by the cDNA library clones (Table 1). The terminal sequences were obtained by Single Primer Amplification Technique (SPAT), using T4 RNA ligase oligonucleotide-mediated amplification as described by Xie et al. [40]. Every region of the genome was determined by sequencing of at least 5 independent clones. Assembly of the sequences was performed using the software Geneious 8.1.5 package (Biomatters).

\subsection{Molecular and Phylogenetic Analysis}

To elucidate its genomic structure, the sequence obtained was analyzed using the software Lasergene SeqBuilder ${ }^{\mathrm{TM}}$ Version 7.0.0 (DNASTAR ${ }^{\circledR}$ Inc., Madison, USA). The 5' - and $3^{\prime}$ - non coding regions (UTRs), the start codon AUG, and the different tripeptides UGA, were also identified with this program. Multiple alignment of the amino acid (aa) sequence of the RdRp to identify the conserved motifs were performed using the program MAFFT version 7 with the default parameters [41]. The secondary structures of the $5^{\prime}$ - and $3^{\prime}$ - UTR were predicted using the MFOLD software (version 3.5) at the MFOLD web site [42]. Phylogenetic analysis was carried out by comparison of the multiple sequence alignments using the software Geneious 8.1.5 package (Biomatters). Phylogenetic trees were constructed using the program Tree View of Geneious 8.1.5 package, and generated by the neighbor-joining method [43] with 1000 bootstrap replicates.

\subsection{Incidence of Mitovirus FodMV1 in the Collection Analyzed}

Extracts enriched in dsRNA were obtained by cellulose column chromatography of a total of 269 F. oxysporum f. sp. dianthi isolates. Presence of mitovirus FodMV1 in some of the extracts was determined by RT-PCR using a primer pair directed to the RdRp of the virus. Primers FodMV1RT, and FodMV1F/FodMV1R, were used for the RT and the PCR, respectively (Table 1). The synthesis of cDNA was performed using $5 \mu \mathrm{L}$ of the dsRNA extracts and the enzyme NZY M-MuLV reverse transcriptase (NZYTech, Lisbon, Portugal). The PCR amplifications were carried out with $5 \mu \mathrm{L}$ of the synthesized cDNA and the GoTaq ${ }^{\circledR}$ DNA polymerase enzyme (Promega Corporation, Madison, WI USA). The products of the RT-PCR amplifications were analyzed by electrophoresis in $1.5 \%$ agarose gels. Amplicons obtained were purified from the gel, sequenced, and analyzed for homology with the sequence of FodMV1 using the program MAFFT v7.

\section{Results}

\subsection{Identification of Viral Infections in a Collection of F. oxysporum f. sp. dianthi Isolates}

In order to detect possible viral infections, a collection of 269 Fusarium oxysporum $\mathrm{f}$. sp. dianthi (Fod) isolates was analyzed in this work (Table 1). All the isolates were obtained from plants and soils 
sampled between 2008 and 2012 in different carnation growing areas in Spain and Colombia, and had been characterized to race and molecular group by multiplex-PCR (Table 1). The presence of putative viral infections was detected in dsRNA extracts by direct observation after agarose gel electrophoresis. Forty out of the 269 isolates analyzed showed presence of a similar dsRNA element with a molecular weight of approximately $2.3 \mathrm{~kb}$ (Figure 1). The dsRNA nature of this element was confirmed based on its resistance to digestion with DNase I and susceptibility to degradation by RNase A at a high salt concentration (not shown). Among the infected isolates, strain Fod 312 was selected to characterize the putative viral dsRNA.

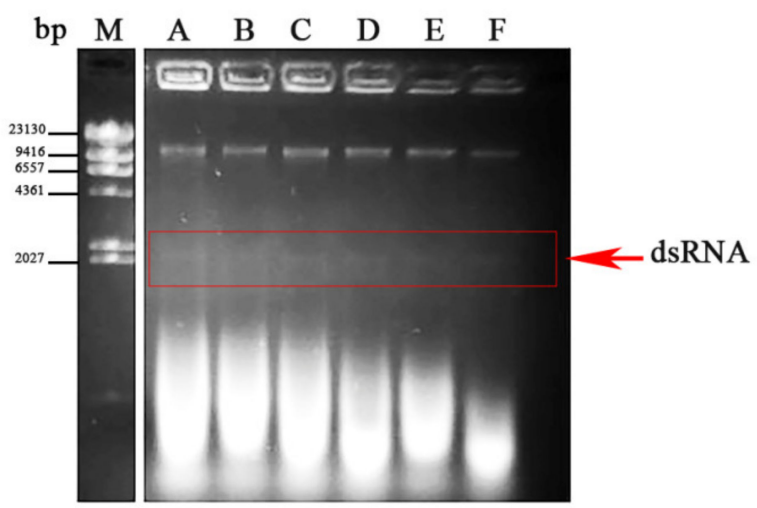

Figure 1. dsRNA-enriched extracts from different isolates of Fusarium oxysporum $\mathrm{f}$. sp. dianthi. Agarose gel electrophoresis of the dsRNA extracts obtained by cellulose column chromatography from different isolates (A-F) of F. oxysporum f. sp. dianthi. M: molecular weight marker II (Roche Diagnostics, Rotkreuz, Switzerland).

\subsection{Molecular Characterization of a Novel Mitovirus Infecting F. oxysporum f.sp. dianthi}

To determine the nucleotide (nt) sequence of the $\sim 2.3 \mathrm{~kb}$ dsRNA element, a total of 53 clones were obtained and sequenced. A first search with some short nt sequences using the BlastX program of the NCBI, revealed that all sequences were related to mitoviral RdRp sequences. From the partial sequences obtained, specific primers were designed to fill in the gaps (Table 1). Finally, single primer amplification technique (SPAT) was used to sequence the $5^{\prime}$ - and $3^{\prime}$-terminal regions. The full-length putative genome was determined to be $2313 \mathrm{nt}$ in length. A new search using BlastX program with the complete sequence showed variable homologies only with viruses in the genus Mitovirus (Table 2).

Table 2. Results from BlastX homology search with Fusarium oxysporum f. sp. dianthi mitovirus 1.

\begin{tabular}{|c|c|c|c|c|c|c|}
\hline Virus $^{a}$ & Acronym & $\begin{array}{c}\text { Length } \\
\text { (nt/aa Size) }\end{array}$ & $\begin{array}{c}\text { Overlap (aa } \\
\text { Identities \%) }\end{array}$ & $\begin{array}{l}\text { Bit score } \\
/ e \text {-value }\end{array}$ & $\begin{array}{l}\text { Query } \\
\text { Cover }\end{array}$ & $\begin{array}{c}\text { GenBank } \\
\text { Accesión No. }\end{array}$ \\
\hline Rhizoctonia solani mitovirus 10 & RsMV10 & $2701 / 752$ & $345 / 563(61)$ & $435 / 6 e-138$ & $70 \%$ & ALD89102.1 \\
\hline Hubei narna-like virus 25 & HNV25 & $2375 / 701$ & $328 / 619(52)$ & $357 / 1 \mathrm{e}-108$ & $77 \%$ & YP_009336494.1 \\
\hline Loramyces juncicola mitovirus 1 & LjMV1 & $2416 / 688$ & $317 / 560(56)$ & $352 / 7 e-11$ & $70 \%$ & AZT88622.1 \\
\hline $\begin{array}{l}\text { Sclerotinia sclerotiorum } \\
\text { mitovirus } 26\end{array}$ & SsMV26 & $1262 / 420$ & $242 / 391(61)$ & $311 / 1 e-94$ & $48 \%$ & AWY10984.1 \\
\hline
\end{tabular}

a The top six distinct viruses returned by BlastX are shown.

Sequence analysis revealed that the genome of the mycovirus identified had a nucleotide composition of A (29.7\%), C (19.7\%), G (21.3\%), and U (29.1\%), with an overall A+U rich content $(58.8 \%)$. Sequence analysis using the DNASTAR program showed the presence of a single large ORF. This coding region started with the first AUG codon in the position 173, and finished with the UAG codon in the position 2200, and was flanked by two UTR regions of 172 nt at the $5^{\prime}$-UTR (nt 1-172) 
and $113 \mathrm{nt}$ at the $3^{\prime}$-UTR (nt 2200-2313). This ORF encodes a putative RdRp of 675 aa residues, with a predicted molecular mass of $76.72 \mathrm{kDa}$. A schematic representation is shown in Figure 2.

A

B
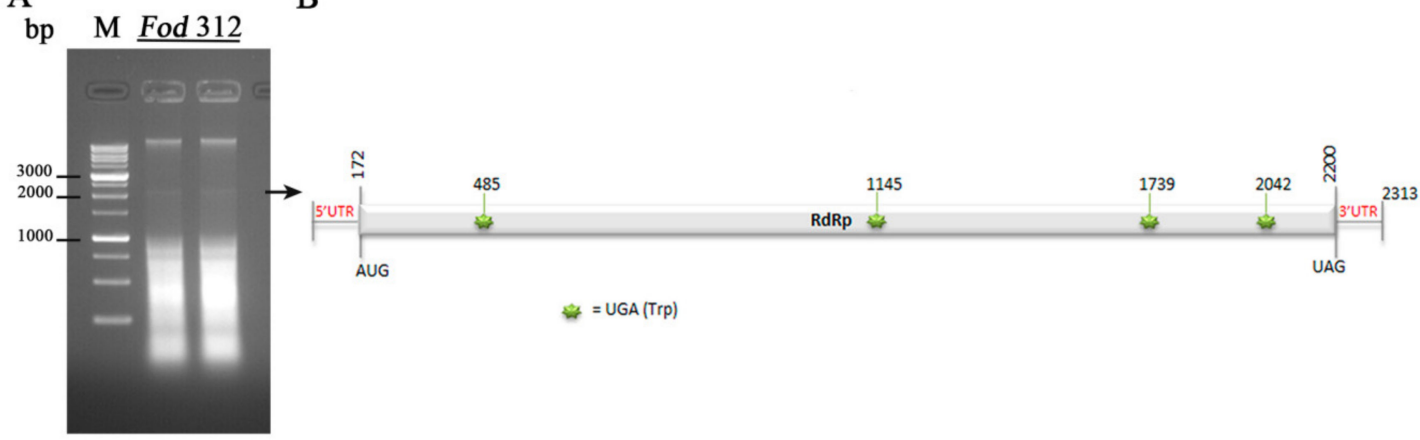

Figure 2. Detection of a mitovirus in isolate Fod 312 and schematic representation of its genomic organization. (A) Agarose gel electrophoresis of the dsRNA-enriched extract obtained by cellulose column chromatography from isolate Fod 312 of Fusarium oxysporum f. sp. dianthi. Lane M: $1 \mathrm{~kb}$ molecular weight marker (Nippon Genetics, Japan). (B) Schematic representation of the genomic organization of Fusarium oxysporum f. sp. dianthi mitovirus 1 (FodMV1). The genome is $2313 \mathrm{bp}$ long and contains a unique ORF that encodes an RNA dependent RNA polymerase (RdRp).

Alignment of the aa sequence of this complete domain with the RdRps of other mycoviruses in the genus Mitovirus, identified six highly conserved motifs (CM-I to VI) which are characteristic of the RdRps [25] (Figure 3). A total of six UGA codons, four in the coding sequence and two in the UTR regions, could be found throughout the complete sequence ().

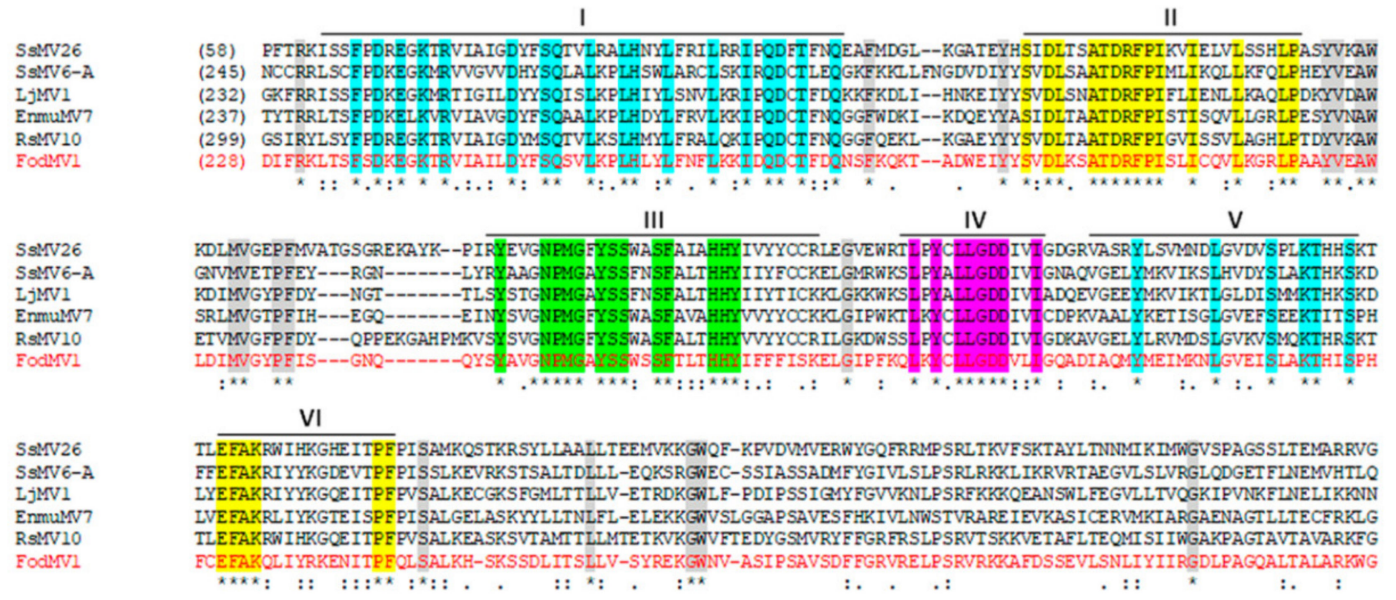

Figure 3. Alignments of the RNA dependent RNA polimerase (RdRp) of FodMV1 and other mitoviruses. Multiple alignment of the aa sequence of the RdRp of FodMV1 and selected viruses in the genus Mitovirus (see Table 3 for acronym, complete name, and GenBank accesion number of the mitoviruses used in this analysis). Alignments were performed using the program MAFFT v7 with the default parameters. Identical residues are indicated with asterisk and color shaded; colons and dots indicate conserved and semi-conserved aa residues, respectively. Conserved domains are indicated with a black line and its number (I-VI).

Since the stem-loop structures at the $5^{\prime}$ - and $3^{\prime}$ - termini are characteristic of mitoviruses, we used MFOLD software to predict the potential secondary structures of the $5^{\prime}$ - and $3^{\prime}$ - terminal sequences of FodMV1. The result obtained revealed that the $5^{\prime}$ - and $3^{\prime}$-UTRs could be folded into a predicted stable stem-loop structure (Figure $4 \mathrm{~A}, \mathrm{~B}$ ), with $\Delta \mathrm{G}$ values of $21.70 \mathrm{kcal} / \mathrm{mol}$ for the $5^{\prime}$-terminal sequence, 
and $24.20 \mathrm{kcal} / \mathrm{mol}$ for the $3^{\prime}$-terminal sequence. Nevertheless, comparison of the nucleotide sequence constituting the stem-loops of FodMV1 and other mitoviruses showed no significant similarities between them.

A

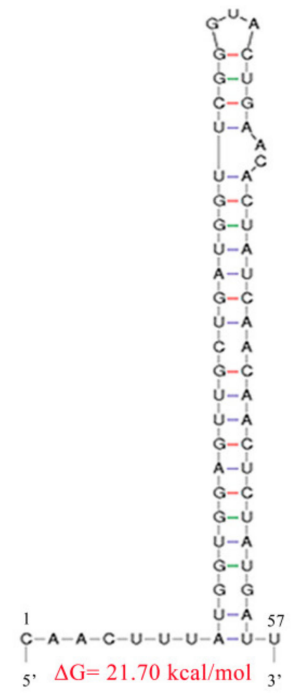

B

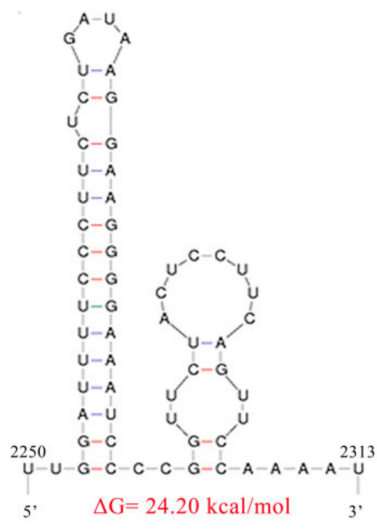

Figure 4. Predicted secondary structures of the terminal sequences of FodMV1. The $5^{\prime}$ - and $3^{\prime}$ - terminal sequences of the positive-strand of the dsRNA could be folded into potentially stable stem-loop structures. (A) Secondary structure of the $5^{\prime}$-UTR. (B) Secondary structure of the $3^{\prime}$-UTR. The MFOLD program was used to predict the secondary structure of the terminal sequences and to calculate the free energy.

Multiple alignment of the complete aa sequence of the RdRp of FodMV1 and the complete aa sequence of the RdRp of other mitoviruses revealed percentages of identity lower than $40 \%$ (Table 2). Therefore, based on the rules of species demarcation criteria about mitoviruses established by the International Committee of Taxonomy for Viruses (ICTV), the mitovirus described in this work should be considered a novel member of this genus, that we have tentatively named Fusarium oxysporum f. sp. dianthi mitovirus 1 (FodMV1). The complete sequence has been deposited in the GeneBank database under the accession number MN586595.

\subsection{Phylogenetic Relationship between FodMV1 and Other Mitoviruses.}

To define the phylogenetic relationship between FodMV1 and other members in the genus Mitovirus, a phylogenetic analysis based on the neighbor-joining method was performed using the full length aa sequence of the viral RdRp. Due to the high number of mitoviruses identified in recent years, a number of them were selected for this analysis (Table 2).

Results obtained showed a distribution of the analyzed mitoviruses in three differentiated clades (clades I, II, and III) (Figure 5). FodMV1 placed in clade III along with other ten fungal mitoviruses, including mitoviruses of phytopathogenic fungi [Hubei narna-like virus 25, Rhizoctonia solani mitovirus 10 (RsMV10), Sclerotinia sclerotiorum mitovirus 6-A (SsMV6-A), Sclerotinia sclerotiorum mitovirus 32 (SsMV32), Sclerotinia sclerotiorum mitovirus 26 (SsMV26), Loramyces juncicola mitovirus 1 (LjMV1),Helicobasidium mompa mitovirus 1-18 (HmMV1-18), and Cryphonectria cubensis mitovirus 1a (CcMV1a)] and mitoviruses of entomopathogenic fungi [Entomorpha muscae mitovirus 7 (EnmuMV7) and Ophiocordyceps sinensis mitovirus 2 (OsMV2)] (Figure 5). 


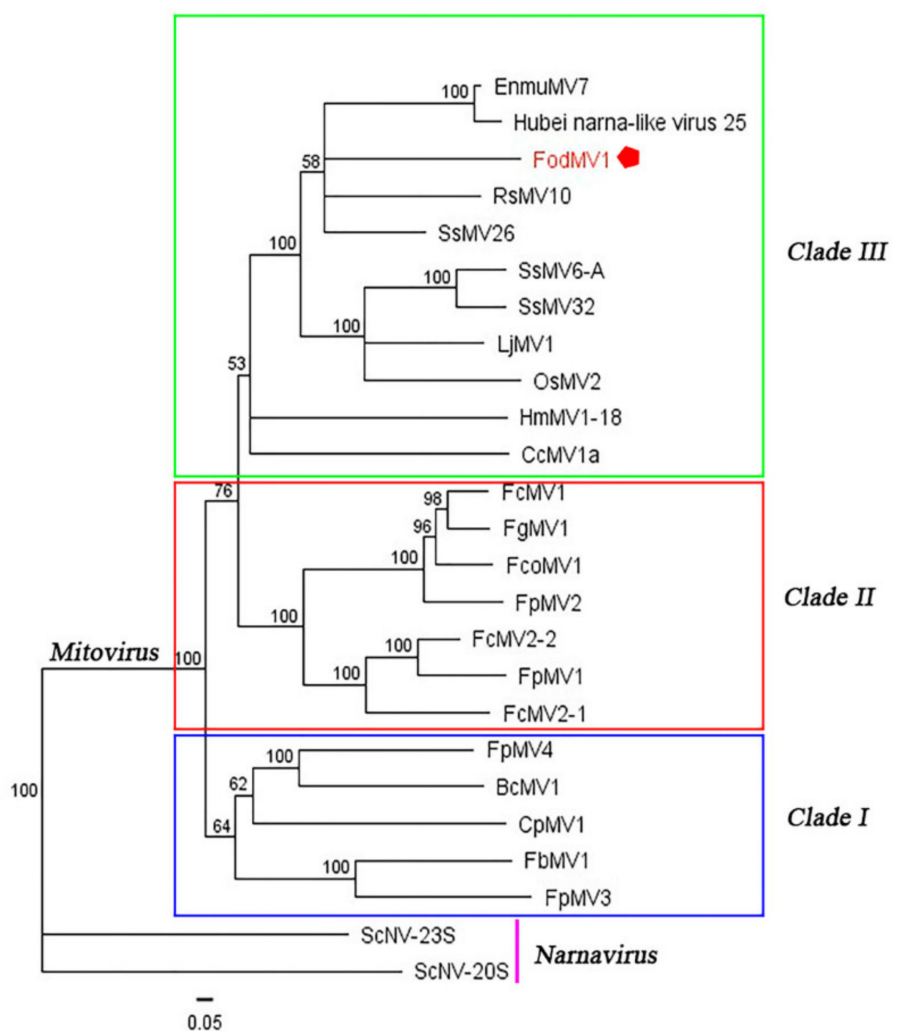

Figure 5. Phylogenetic analysis of FodMV1 based on the aa sequence of the RdRp. Neighbor-joining consensus tree of FodMV1 and a number of selected mitoviruses (See Table 2) based on the full length aa sequence of the viral RdRp. Color boxes indicate the different clades obtained. The phylogenetic tree was constructed using Tree View of Geneious 8.1.5 package (Biomatters), and generated by the neighbor-joining method with 1000 bootstrap replicates.

\subsection{Incidence of Mitovirus FodMV1 in the Collection Analyzed}

Of the 269 isolates analyzed by cellulose column chromatography, 40 showed presence of a similar dsRNA segment with an estimated molecular weight of $\sim 2.3 \mathrm{~kb}$. Characterization of this dsRNA element from one of the isolates (isolate Fod 312) showed that it was a new member of the genus Mitovirus, that we have named Fusarium oxysporum f. sp. dianthi mitovirus 1 (FodMV1).

To determine if the dsRNA element observed in the remaining 39 isolates corresponded to mitovirus FodMV1, we carried out amplifications by RT-PCR using the corresponding dsRNA extracts and specific primers designed from the nt sequence of the RdRp of FodMV1. The expected amplicon of approximately $0.7 \mathrm{~kb}$ was obtained as a result of the RT-PCRs in 22 of the 39 isolates analyzed (Figure 6A). These amplicons were purified from the agarose gel and sequenced. Subsequent multiple alignment between the corresponding region of the RdRp of FodMV1 and the nt sequences of the amplicons obtained from the 22 different Fod isolates showed nt identities between 95\%-100\% (Table 3). Identity was complete (100\%) among the four dsRNA sequences identified in the 4 isolates from Colombia (Figure 6B), and between 95\%-97\% for the dsRNAs from the remaining 18 isolates, all of them originating from Spain. Regardless of the geographic origin, all FodMV1-infected isolates were of the same R2I race-group (Table 3). 
Table 3. Isolates of Fusarium oxysporum f. sp. dianthi infected with mitovirus FodMV1.

\begin{tabular}{|c|c|c|c|c|c|}
\hline Host Isolate ${ }^{a}$ & $\begin{array}{c}\text { RdRp } \\
\text { (\% nt } \\
\text { Identity) }^{b}\end{array}$ & $\begin{array}{l}\text { Geographic } \\
\text { Origin }^{c}\end{array}$ & Source & Year & $\begin{array}{l}\text { Race group Assignation } \\
\text { by PCR Pattern }\end{array}$ \\
\hline Fod 124 & $97 \%$ & Chipiona(Ca) & Plant & 2009 & R2I \\
\hline Fod 233 & $96 \%$ & Chipiona(Ca) & Plant & 2011 & R2I \\
\hline Fod 235 & $95 \%$ & Chipiona(Ca) & Plant & 2011 & R2I \\
\hline Fod 237 & $95 \%$ & Chipiona(Ca) & Plant & 2011 & R2I \\
\hline Fod 253 & $95 \%$ & Chipiona(Ca) & Plant & 2011 & R2I \\
\hline Fod 219 & $95 \%$ & Lebrija(Se) & Plant & 2011 & R2I \\
\hline Fod 215 & $97 \%$ & Lebrija(Se) & Plant & 2011 & R2I \\
\hline Fod 221 & $95 \%$ & Lebrija(Se) & Plant & 2011 & R2I \\
\hline Fod 327 & $96 \%$ & Chipiona(Ca) & Plant & 2012 & R2I \\
\hline Fod 328 & $95 \%$ & Chipiona(Ca) & Plant & 2012 & R2I \\
\hline Fod 330 & $96 \%$ & Chipiona(Ca) & Plant & 2012 & R2I \\
\hline Fod 331 & $97 \%$ & Chipiona(Ca) & Plant & 2012 & R2I \\
\hline Fod 332 & $95 \%$ & Chipiona(Ca) & Plant & 2012 & R2I \\
\hline Fod 333 & $96 \%$ & Chipiona(Ca) & Plant & 2012 & R2I \\
\hline Fod 334 & $97 \%$ & Chipiona(Ca) & Plant & 2012 & R2I \\
\hline Fod 341.1 & $95 \%$ & Chipiona(Ca) & Plant & 2012 & R2I \\
\hline Fod 337 & $97 \%$ & Chipiona(Ca) & Soil & 2012 & R2I \\
\hline Fod 338 & $95 \%$ & Chipiona(Ca) & Soil & 2012 & R2I \\
\hline Fod 340 & $96 \%$ & Chipiona(Ca) & Soil & 2012 & R2I \\
\hline Fod 310 & $100 \%$ & Colombia & Plant & 2012 & R2I \\
\hline Fod 311 & $100 \%$ & Colombia & Plant & 2012 & R2I \\
\hline Fod 313 & $100 \%$ & Colombia & Soil & 2012 & R2I \\
\hline
\end{tabular}

(a) The dsRNA from each isolate was analyzed by RT-PCR using specific primers FodMV1F/FodMV1R directed to the RdRp sequence of FodMV1. ${ }^{(b)}$ Percentage of identity between the nucleotide sequences of the $0.7 \mathrm{~kb}$ amplicon obtained with each isolate and the correspondent sequence of FodMV1. (c) Ca = Cádiz province, Se = Sevilla province. (d) Race-group assignation by molecular markers, as described in Gómez-Lama Cabanás et al. [38]. $\mathrm{R} 2 \mathrm{I}=$ race 2 molecular group I.

A

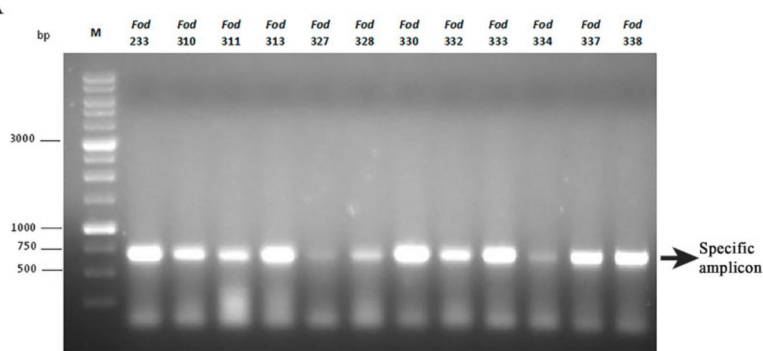

B

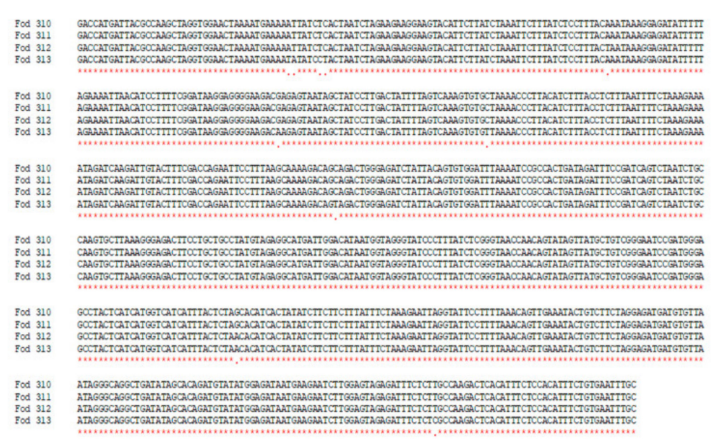

Figure 6. Isolates of Fusarium oxysporum $\mathrm{f}$. sp. dianthi infected with mitovirus FodMV1, and alignment of the partial nucleotide sequence of the RdRp of FodMV1 from different isolates. (A) Specific amplicons obtained after RT-PCR of the dsRNA extracts using specific primers for the RdRp sequence of FodMV1. M: $1 \mathrm{~kb}$ molecular weight marker (Nippon Genetics, Japan). (B) Multiple alignment of the amplicons obtained by RT-PCR using specific primers for the RdRp of FodVM1 and dsRNA extracts from isolates Fod 310, 311, 312, and 313 of Fusarium oxysporum f. sp. dianthi from Colombia. Analysis was carried out with the program MAFFT v7. 


\section{Discussion}

In this work, we have identified and characterized a dsRNA element found in an isolate of Fusarium oxysporum $\mathrm{f}$. sp. dianthi, which represents the genome of a putative mycovirus. Homology BlastX searches revealed variable sequence similarities only with the aa sequence of other mycoviruses in the genus Mitovirus. Based on this result, we propose that this dsRNA (replicative form) is a novel member of the genus Mitovirus in the family Narnaviridae, that we have named Fusarium oxysporum $\mathrm{f}$. sp. dianthi mitovirus 1 (FodMV1).

Due to their possible use as biological control agents [3-7,16,17], and to the current low cost of mass sequencing techniques [18,29], the description of new mycoviruses, in general, and of new mitoviruses in particular, is increasing considerably in recent times. Mitoviruses have been found in many phytopathogenic fungi, including both ascomycetes and basidiomycetes [23-25,31-37], and also in many entomopathogenic fungi $[8,13,14]$. Nevertheless, among the hundreds of mitoviruses described so far, none has been identified infecting a strain of the important phytopathogenic species F. oxysporum. Mitovirus FodMV1 has been detected in a strain of F. oxysporum f. sp. dianthi and, therefore, is the first mitovirus described infecting F. oxysporum.

Based on the molecular characterization and the genomic organization, Ghabrial and Suzuki described mitoviruses as simple naked mycoviruses whose RNA genomes encode only an RdRp protein, and that exist as RNA-RdRp nucleoprotein complexes [3]. Mitoviruses are also characterized by replicating within the mitochondria of the host $[20,26,27]$. Consequently, as in the case of many fungal and plant mitochondrial genomes, mitoviruses have a common property of A-U richness [27,44]. Another consequence of mitoviruses being replicated inside the mitochondria is that in the mitovirus genome, the UGA codon encodes the aa tryptophan, rather than acting as a stop codon as in the universal genetic code [26]. Our results show that the genome of FodMV1 does indeed have a high percentage of $\mathrm{A}+\mathrm{U}(58.8 \%)$, and also contains a total of 6 UGA codons, two of them in the $5^{\prime}$ - and $3^{\prime}$ non coding regions, and four in the ORF sequence. Another characteristic of mitovirus genomic RNAs is the presence of stem-loop structures at both the $5^{\prime}$ - and $3^{\prime}$ - ends. These structures may play important roles in mitoviral replication and in the protection of the naked ssRNA from degradation $[25,44]$. Moreover, stem-loop structures are common RdRp recognition sites [45,46]. In the present study, we have found that the $5^{\prime}$ - and $3^{\prime}$-UTR regions of FodMV1, as in other mitoviruses, can be folded into potentially stable stem-loop structures. However, these 5'- and 3'- loop-sequences of FodMV1 showed no significant similarity with the corresponding sequences of other mitoviruses.

The genome of FodMV1 contains a single ORF that encodes an RdRp. Multiple alignment of the aa sequence of the RdRp of FodMV1 and other mitoviruses, allowed the identification of the six conserved motifs (I-VI) characteristic of the RdRps. According to Hong et al. [25], of these motifs, motif I is considered to be characteristic of the genus Mitovirus. Comparison of the complete nt and aa sequences of FodMV1 and other mycoviruses in the genus Mitovirus showed a generally limited similarity. The highest percentages of $\mathrm{nt}$ and aa identities were found with Sclerotinia sclerotiorum mitovirus 26 ( $49 \%$ and $40 \%$, respectively), Rhizoctonia solani mitovirus 10 ( $44 \%$ and 38\%, respectively), Entomophthora muscae mitovirus 7 ( $42 \%$ and $34 \%$, respectively), Hubei narna-like virus $(42 \%$ and $33 \%$, respectively), Loramyces juncicola mitovirus 1 (39\% and 31\%, respectively), Ophiocordyceps sinensis mitovirus 2 (39\% and $27 \%$, respectively), and Sclerotinia sclerotiorum mitovirus 32 (37\% and $28 \%$, respectively). The rules of species demarcation criteria determined by the ICTV establish that the aa sequence identities of putative RdRp proteins should be less than $40 \%$ between different mitovirus species, and greater than $90 \%$ in the case of strains of the same mitovirus species [19]. According to this, FodMV1 should be considered a new species of the genus Mitovirus.

To provide further evidence of the relationship of FodMV1 with previously reported mitoviruses, we have carried out a phylogenetic analysis using the RdRp aa sequence. In previous phylogenetic analyses, mitoviruses were distributed into three major clades (clade I, II, and III) [24,37], and specifically, Fusarium mitoviruses clustered mostly in clade II [37]. Our results showed that FodMV1 clustered in a clade other than that of the rest of mitoviruses described infecting Fusarium spp., being more closely 
related to mitoviruses that infect other phytopathogenic fungi or even entomopathogenic fungi. This result seems to indicate that so far, FodMV1 is the most different among the mitoviruses described infecting Fusarium species.

To determine the incidence of FodMV1 infections, a total of 269 isolates of Fusarium oxysporum $\mathrm{f}$. sp. dianthi obtained from different locations were analyzed. The dsRNA-enriched extracts obtained by cellulose column chromatography showed the presence of a dsRNA fragment with a molecular weight similar to that of FodMV1 in a total of 39 isolates. RT-PCR amplification of these dsRNA extracts using specific primers directed to the RdRp of FodMV1 produced the expected amplicon of approximately $0.7 \mathrm{~kb}$ in 22 of the 39 isolates analyzed. Sequencing of the amplicons and comparison of the sequences obtained with that of FodMV1 showed nt identities between $95 \%$ and $100 \%$ in all the cases. Identity was complete $(100 \%)$ among the four dsRNA sequences identified in the 4 isolates from Colombia, and ranged between $95 \%-97 \%$ for the dsRNA from the rest of the isolates, all of them originating from Spain. Event thought these $0.7 \mathrm{~kb}$ sequences are partial, the (almost) complete identity with the correspondent sequence of mitovirus FodMV1 strongly suggests that each viral sequence corresponds to a strain of the same mitovirus FodMV1. The fact that all the virus-infected isolates were of the same R2I race-group and, therefore, of the same vegetative compatibility group [47], supports the hypothesis that a transmission of the virus could have taken place by hyphal anastomosis between isolates. Interestingly, the higher identity $(100 \%)$ found among the four strains of FodMV1 from Colombia could be an indicator that the viral infection in these isolates is more recent than that present in the isolates from Spain. Presence of the same mitovirus species infecting isolates from two geographical areas as distant as Spain and Colombia could be explained by the dispersion of the viral infection through the commercialization of infected carnation cuttings between both countries.

Supplementary Materials: The following are available online at http://www.mdpi.com/1999-4915/12/3/279/s1, Figure S1: Complete nucleotide sequence of Fusarium oxysporum f. sp dianthi mitovirus 1 (FodMV1), Table S1: Specific primers and adapters used for the sequencing of FodMV1, Table S2: Amino acid identities between FodMV1 and other mitoviruses.

Author Contributions: Conceptualization, A.T.-T. and E.P.-A.; Data curation, A.T.-T.; Formal analysis, A.T.-T.; Funding acquisition, E.P.-A.; Investigation, A.T.-T. and E.P.-A.; Methodology, A.T.-T. and E.P.-A.; Supervision, E.P.-A.; Writing - original draft, A.T.-T. and E.P.-A. All authors have read and agreed to the published version of the manuscript.

Funding: This research was supported by Grant AGL 2016-80048-R from the Spanish Ministry of Science and Innovation, co-funded by the European Union (FEDER funds).

Acknowledgments: This research was supported by Grant AGL 2016-80048-R from the Spanish Ministry of Science and Innovation, co-funded by the European Union (FEDER funds).

Conflicts of Interest: The authors declare no conflict of interest. The funders had no role in the design of the study; in the collection, analyses, or interpretation of data; in the writing of the manuscript, or in the decision to publish the results.

\section{References}

1. Garibaldi, A.; Gullino, M.L. Attempts of biocontrol of fusarium-wilt of carnation in Italy. Phytopathology $1987,77,1721$.

2. Baayen, R.P. Fusarium wilt of carnation. Disease development, resistance mechanism of the host and taxonomy of the pathogen. Ph.D. Thesis, Degree-Granting University of Utretcht, Utrecht, The Netherlands, 1988.

3. Ghabrial, S.A.; Suzuki, N. Viruses of plant pathogenic fungi. Annu Rev. Phytopathol 2009, 47, 353-384. [CrossRef] [PubMed]

4. Pearson, M.N.; Beever, R.E.; Boine, B.; Arthur, K. Mycoviruses of filamentous fungi and their relevance to plant pathology. Mol Plant. Pathol 2009, 10, 115-128. [CrossRef] [PubMed]

5. Son, M.; Yu, J.; Kim, K.H. Five questions about mycoviruses. Plos Pathog 2015, 11, e1005172. [CrossRef] [PubMed]

6. Ghabrial, S.A.; Caston, J.R.; Jiang, D.; Nibert, M.L.; Suzuki, N. 50-plus years of fungal viruses. Virology 2015, 356-368, 479-480. [CrossRef] 
7. Abbas, A. A Review Paper on Mycoviruses. J. Plant. Pathol. Microbiol. 2016, 7, 2. [CrossRef]

8. Nibert, M.L.; Debat, H.J.; Manny, A.R.; Grigoriev, I.V.; De Fine Licht, H.H. Mitovirus and mitochondrial coding sequences from basal fungus Entomophthora muscae. Viruses 2019, 11, 351. [CrossRef]

9. King, A.M.; Adams, M.J.; Lefkowitz, E.J. Virus taxonomy: Classification and nomenclature of viruses: Ninth Report of the International Committee on Taxonomy of Viruses; Elsevier: Amsterdam, The Netherlands, 2011.

10. Herrero, N.; Dueñas, E.; Quesada-Moraga, E.; Zabalgogeazcoa, I. Prevalence and diversity of viruses in the entomopathogenic fungus Beauveria bassiana. Appl Environ. Microbiol. 2012, 78, 8523-8530. [CrossRef]

11. Kotta-Loizou, I.; Coutts, R.H.A. Studies on the virome of the entomopathogenic fungus Beauveria bassiana reveal novel dsRNA elements and mild hypervirulence. PLoS Pathog. 2017, 13, e1006183. [CrossRef]

12. Ikeda, Y.; Shimura, H.; Kitahara, R.; Masuta, C.; Ezawa, T. A novel virus-like double-stranded RNA in an obligate biotroph arbuscular mycorrhizal fungus: A hidden player in mycorrhizal symbiosis. Mol. Plant. Microbe Interact. 2012, 25, 1005-1012. [CrossRef]

13. Cook, S.; Chung, B.Y.; Bass, D.; Moureau, G.; Tang, S.; McAlister, E.; Culverwell, C.L.; Glücksman, E.; Wang, H.; Brown, T.D.; et al. Novel virus discovery and genome reconstruction from field RNA samples reveals highly divergent viruses in dipteran hosts. PLoS ONE 2013, 8, e80720. [CrossRef] [PubMed]

14. Shi, M.; Lin, X.D.; Tian, J.H.; Chen, L.J.; Chen, X.; Li, C.X.; Qin, X.C.; Li, J.; Cao, J.P.; Eden, J.S.; et al. Redefining the invertebrate RNA virosphere. Nature 2016, 540, 539-543. [CrossRef] [PubMed]

15. Xie, J.; Jiang, D. New insights into mycoviruses and exploration for the biological control of crop fungal diseases. Annu Rev. Phytopathol. 2014, 52, 45-68. [CrossRef] [PubMed]

16. Lemus-Minor, C.G.; Cañizares, M.C.; García-Pedrajas, M.D.; Pérez-Artés, E. Fusarium oxysporum f. sp. dianthi virus 1 accumulation is correlated with changes in virulence and other phenotypic traits of its fungal host. Phytopathology 2018, 108, 957-963. [CrossRef]

17. Yu, X.; Li, B.; Fu, Y.; Xie, J.; Cheng, J.; Ghabrial, S.A.; Li, G.; Yi, X.; Jiang, D. Extracellular transmission of a DNA mycovirus and its use as a natural fungicide. Proc. Natl. Acad. Sci.USA 2013, 110, 1452-1457. [CrossRef]

18. Gilbert, K.B.; Holcomb, E.E.; Allscheid, R.L.; Carrington, J.C. Hiding in plain sight: New virus genomes discovered via a systematic analysis of fungal public transcriptomes. PLoS ONE 2019, 14, e0219207. [CrossRef]

19. Hillman., B.I.; Esteban., R. Narnaviridae. In Virus Taxonomy: Classification and nomenclature of viruses. Ninth report of the International Committee on Taxonomy of Viruses; King, A.M.Q., Adams, M.J., Carstens, E.B., Lefkowitz, E.J., Eds.; Elsevier: San Diego, CA, USA, 2011; pp. 1055-1060.

20. Hillman, B.I.; Cai, G. The family Narnaviridae: Simplest of RNA viruses. Adv. Virus Res. 2013, 86, 149-176. [CrossRef]

21. Nibert, M.L.; Vong, M.; Fugate, K.K.; Debat, H.J. Evidence for contemporary plant mitoviruses. Virology 2018, 518, 14-24. [CrossRef]

22. Nerva, L.; Vigani, G.; Di Silvestre, D.; Ciuffo, M.; Forgia, M.; Chitarra, W.; Turina, M. Biological and molecular characterization of Chenopodium quinoa mitovirus 1 reveals a distinct sRNA response compared to cytoplasmic RNA viruses. J. Virol. 2019, 93, e01998-e18. [CrossRef]

23. Wu, M.; Zhang, L.; Li, G.; Jiang, D.; Ghabrial, S.A. Genome characterization of a debilitation-associated mitovirus infecting the phytopathogenic fungus Botrytis cinerea. Virology 2010, 406, 117-126. [CrossRef]

24. Xu, Z.; Wu, S.; Liu, L.; Cheng, J.; Fu, Y.; Jiang, D.; Xie, J. A mitovirus related to plant mitochondrial gene confers hypovirulence on the phytopathogenic fungus Sclerotinia sclerotiorum. Virus Res. 2015, 197, 127-136. [CrossRef] [PubMed]

25. Hong, Y.; Dover, S.L.; Cole, T.E.; Brasier, C.M.; Buck, K.W. Multiple mitochondrial viruses in an isolate of the Dutch elm disease fungus Ophiostoma novo-ulmi. Virology 1999, 258, 118-127. [CrossRef] [PubMed]

26. Nibert, M.L. Mitovirus UGA(Trp) codon usage parallels that of host mitochondria. Virology 2017, 507, 96-100. [CrossRef] [PubMed]

27. Paquin, B.; Laforest, M.J.; Forget, L.; Roewer, I.; Wang, Z.; Longcore, J.; Lang, B.F. The fungal mitochondrial genome project: Evolution of fungal mitochondrial genomes and their gene expression. Curr. Genet. 1997, 31, 380-395. [CrossRef] [PubMed]

28. Liu, S.; Xie, J.; Cheng, J.; Li, B.; Chen, T.; Fu, Y.; Li, G.; Wang, M.; Jin, H.; Wan, H.; et al. Fungal DNA virus infects a mycophagous insect and utilizes it as a transmission vector. Proc. Natl. Acad. Sci. USA 2016, 113, 12803-12808. [CrossRef] [PubMed] 
29. Marzano, S.-Y.L.; Nelson, B.D.; Ajayi-Oyetunde, O.; Bradley, C.A.; Hughes, T.J.; Hartman, G.L.; Eastburn, D.M.; Domier, L.L. Identification of diverse mycoviruses through metatranscriptomics characterization of the viromes of five major fungal plant pathogens. J. Virol. 2016, 90, 6846-6863. [CrossRef] [PubMed]

30. Polashock, J.J.; Bedker, P.J.; Hillman, B.I. Movement of a small mitochondrial double-stranded RNA element of Cryphonectria parasitica: Ascospore inheritance and implications for mitochondrial recombination. Mol. Gen. Genet. 1997, 256, 566-571. [CrossRef]

31. Xie, J.; Ghabrial, S.A. Molecular characterization of two mitoviruses co-infecting a hypovirulent isolate of the plant pathogenic fungus Sclerotinia sclerotiorum. Virology 2012, 428, 77-85. [CrossRef]

32. Deng, F.; Xu, R.; Boland, G.J. Hypovirulence-associated double-stranded RNA from Sclerotinia homoeocarpa is conspecific with Ophiostoma novo-ulmi mitovirus 3a-Ld. Phytopathology 2003, 93, 1407-1414. [CrossRef]

33. Lakshman, D.K.; Jian, J.; Tavantzis, S.M. A double-stranded RNA element from a hypovirulent strain of Rhizoctonia solani occurs in DNA form and is genetically related to the pentafunctional AROM protein of the shikimate pathway. Proc. Natl. Acad. Sci. USA 1998, 95, 6425-6429. [CrossRef]

34. Vainio, E.J.; Martínez-Álvarez, P.; Bezos, D.; Hantula, J.; Diez, J.J. Fusarium circinatum isolates from northern Spain are commonly infected by three distinct mitoviruses. Arch. Virol. 2015, 160, 2093-2098. [CrossRef] [PubMed]

35. Osaki, H.; Sasaki, A.; Nomiyama, K.; Sekiguchi, H.; Tomioka, K.; Takehara, T. Isolation and characterization of two mitoviruses and a putative alphapartitivirus from Fusarium spp. Virus Genes 2015, 50, 466-473. [CrossRef] [PubMed]

36. Osaki, H.; Sasaki, A.; Nomiyama, K.; Tomioka, K. Multiple virus infection in a single strain of Fusarium poae shown by deep sequencing. Virus Genes 2016, 52, 835-847. [CrossRef] [PubMed]

37. Mizutani, Y.; Abraham, A.; Uesaka, K.; Kondo, H.; Suga, H.; Suzuki, N.; Chiba, S. Novel mitoviruses and a unique tymo-like virus in hypovirulent and virulent strains of the fusarium head blight bungus, Fusarium boothii. Viruses 2018, 10, 584. [CrossRef]

38. Gómez-Lama Cabanás, C.; Valverde-Corredor, A.; Pérez-Artés, E. Molecular analysis of Spanish populations of Fusarium oxysporum $\mathrm{f}$. sp dianthi demonstrates a high genetic diversity and identifies virulence groups in races 1 and 2 of the pathogen. Eur. J. Plant. Pathol 2012, 132, 561-576. [CrossRef]

39. Valverde, R.A.; Nameth, S.T.; Jordan, R.L. Analysis of double-stranded-RNA for plant-virus diagnosis. Plant. Dis. 1990, 1990 74, 255-258.

40. Xie, J.; Wei, D.; Jiang, D.; Fu, Y.; Li, G.; Ghabrial, S.; Peng, Y. Characterization of debilitation-associated mycovirus infecting the plant-pathogenic fungus Sclerotinia sclerotiorum. J. Gen. Virol. 2006, 87, 241-249. [CrossRef]

41. Katoh, K.; Standley, D.M. MAFFT multiple sequence alignment software version 7: Improvements in performance and usability. Mol. Biol. Evol. 2013, 30, 772-780. [CrossRef]

42. Zuker, M.; Mathews, D.H.; Turner, D.H. Algorithms and Thermodynamics for RNA Secondary Structure Prediction: A Practical Guide. In RNA Biochemistry and Biotechnology; Barciszewski, J., Clark, B.F.C., Eds.; NATO ASI Series; Kluwer Academic Publishers: Dordrecht, The Netherlands, 1999; pp. 11-43.

43. Saitou, N.; Nei, M. The neighbor-joining method: A new method for reconstructing phylogenetic trees. Mol. Biol. Evol. 1987, 4, 406-425. [CrossRef]

44. Hong, Y.; Cole, T.E.; Brasier, C.M.; Buck, K.W. Evolutionary relationships among putative RNA-dependent RNA polymerases encoded by a mitochondrial viruslike RNA in the dutch elm disease fungus, Ophiostoma novo-ulmi, by other viruses and virus-like RNAs and by the arabidopsis mitochondrial genome. Virology 1998, 246, 158-169. [CrossRef]

45. Buck, K.W. Comparison of the replication of positive-stranded RNA viruses of plants and animals. Adv. Virus Res. 1996, 47, 159-251. [PubMed]

46. Buck, K.W.; Brasier, C.M. Viruses of the dutch elm disease fungus. In dsRNA Genetic Elements: Concepts and Applications in Agriculture, Forestry and Medicine; Tavantzis, S.M., Ed.; CRC Press LCC: Boca Raton, FL, USA, 2002; pp. 165-190.

47. Gómez-Lama Cabanás, C.; Pérez-Artés, E. New evidence of intra-race diversity in Fusarium oxysporum f. sp. dianthi populations based on Vegetative Compatibility Groups. Eur. J. Plant. Pathol. 2014, 139, 445-451.

(C) 2020 by the authors. Licensee MDPI, Basel, Switzerland. This article is an open access article distributed under the terms and conditions of the Creative Commons Attribution (CC BY) license (http://creativecommons.org/licenses/by/4.0/). 